\title{
The arrestin-domain containing protein AdcA is a response element to stress
}

\author{
Clémence Habourdin ${ }^{1,2,3}$, Gérard Klein ${ }^{1,2,3}$, Tsuyoshi Araki ${ }^{4}$, Jeffrey G Williams ${ }^{4}$ and Laurence Aubry ${ }^{1,2,3,5^{*}}$
}

\begin{abstract}
Background: Cell behaviour is tightly determined by sensing and integration of extracellular changes through membrane detectors such as receptors and transporters and activation of downstream signalling cascades. Arrestin proteins act as scaffolds at the plasma membrane and along the endocytic pathway, where they regulate the activity and the fate of some of these detectors. Members of the arrestin clan are widely present from unicellular to metazoa, with roles in signal transduction and metabolism. As a soil amoeba, Dictyostelium is frequently confronted with environmental changes likely to compromise survival. Here, we investigated whether the recently described arrestin-related protein AdcA is part of the cell response to stresses.

Results: Our data provide evidence that AdcA responds to a variety of stresses including hyperosmolarity by a transient phosphorylation. Analysis in different mutant backgrounds revealed that AdcA phosphorylation involves pathways other than the DokA and CGMP-dependent osmostress pathways, respectively known to regulate PKA and STATc, key actors in the cellular response to conditions of hyperosmolarity. Interestingly, however, both AdcA and STATc are sensitive to changes in the F-actin polymerization status, suggesting a common primary sensor/ trigger and linking the stress-sensitive kinase responsive for AdcA phosphorylation to the actin cytoskeleton. We also show that STATc-dependent transcriptional activity is involved for the timely dephosphorylation of AdcA in cells under stress.
\end{abstract}

Conclusion: Under osmotic stress, AdcA undergoes a phosphorylation-dephosphorylation cycle involving a stress-sensitive kinase and the transcription regulator STATc. This transient post-transcriptional modification may allow a regulation of AdcA function possibly to optimize the cellular stress response.

Keywords: Arrestin, Stress, STAT transcription factor, Hyperosmolarity, Dictyostelium, Phosphorylation

\section{Background}

Cells are continuously subjected to environmental cues that determine their behaviour in terms of motility, adhesion, growth and differentiation. Their capacity to sense and respond to external stimuli largely relies on membrane proteins including receptors, adhesion molecules, channels and transporters that function as sensors and signal transducers. In the cytoplasm, adaptor proteins from the arrestin clan play key roles in the signal relay, acting downstream of transmembrane spanning proteins at the plasma membrane or/and along the endocytic pathway. A well-characterized system is the coupling of $\beta$ arrestins to ligand-activated G-protein coupled receptors

\footnotetext{
* Correspondence: laubry@cea.fr

${ }^{1}$ CEA, iRTSV, Laboratoire Biologie à Grande Echelle, F-38054 Grenoble, France ${ }^{2}$ Université Joseph Fourier, F-38041 Grenoble, France

Full list of author information is available at the end of the article
}

(GPCRs) allowing their temporal desensitization, their trafficking to specific endocytic compartments and the activation of secondary signalling cascades [1-5]. Over the past few years, a family of arrestin-related proteins have been identified in mammals (Arrdcs) as well as in lower organisms such as fungi (ARTs) and amoebae (Adcs) [6-9]. Recent data indicated that ART adaptor proteins regulate the fate of plasma membrane permeases through a conserved ubiquitination-dependent pathway in response to changes in nutritive or $\mathrm{pH}$ conditions. ARTs allow the recruitment of the Rsp5 ubiquitin ligase to the vicinity of membrane targets, leading to their ubiquitination and subsequent degradation [8,10-13]. The functions of Arrdcs are still under investigation but recent studies indicate that these proteins could similarly behave as ubiquitin ligase adaptors allowing the regulated ubiquitination of plasma

\section{Biomed Central}

(c) 2013 Habourdin et al.; licensee BioMed Central Ltd. This is an open access article distributed under the terms of the Creative Commons Attribution License (http://creativecommons.org/licenses/by/2.0), which permits unrestricted use, distribution, and reproduction in any medium, provided the original work is properly cited. 
membrane targets and their ensuing downregulation $[14,15]$.

The social amoeba Dictyostelium harbours 6 arrestindomain containing proteins (AdcA to F). Their expression is highly regulated during the developmental cycle but the role of the Adcs at the different stages of the developmental program is completely enigmatic. In contrast to canonical visual and $\beta$-arrestins, the Dictyostelium Adcs contain additional functional domains besides the arrestin core, including lipid binding- and protein-protein interaction domains [7]. The AdcA protein is extended on both sides of the arrestin core by an N-terminal histidine-rich domain and a C-terminal FYVE domain. This latter domain contributes to the constitutive association of AdcA to the endocytic pathway [16]. The AdcA protein is most highly expressed during the unicellular growth phase of Dictyostelium. At this stage, cells are faced with a broad range of environmental changes, ranging from hypo- or hyperosmotic conditions to nutrient deprivation and their survival in such conditions relies on multiple and complex strategies. Hyperosmotic challenge activates an intricate transcriptionally regulated osmostress response [17].

Our data presented here provide evidence that AdcA undergoes a massive phosphorylation in response to a variety of stresses, including hypertonicity, and that AdcA dephosphorylation is partly dependent on a STATc pathway and correlates with cell recovery, raising the question of a possible role of AdcA in stress response.

\section{Results}

AdcA is multiphosphorylated in response to sorbitol-induced hyperosmotic stress

In preliminary experiments, we observed that changes of external medium (12 mM Na,K-Pi buffer vs HL5 axenic medium) affected the electrophoretic pattern of the AdcA protein. We therefore examined the impact of various cellular stresses especially osmotic stress to determine the signal(s) responsible for this modification. In our assays, exponentially growing cells were centrifuged, resuspended in fresh nutritive medium and left to recover in shaking suspension for at least $1 \mathrm{~h} 30$ prior to stress application. This protocol avoided, thereafter, any possible stress due to centrifugation (transient anaerobiosis, mechanical constrains, temperature shift) and nutrient depletion. In these conditions, in KAx-3 cells, AdcA was detected as a major higher mobility form and occasionally a minor slower form (Figure 1A, bands 1 and 2). Addition of $200 \mathrm{mM}$ sorbitol to the medium led to a massive and transient modification of the protein. Within minutes after sorbitol addition, the electrophoretic mobility of AdcA gradually decreased with the accumulation of band 2 and the appearance of a slow migrating third band (Figure 1A, band 3). A similar mobility change was observed with the $\mathrm{C}$-terminally tagged versions of $A d c A, A_{d c} A_{G F P}$ (Figure 2) and $\operatorname{AdcA}_{\text {myc }}$ (not shown) indicating that the tagged and overexpressed proteins behave as the endogenous AdcA. Maximal amount of band 3 occurred past 30 min post stress application (Figure 1A, right panel). Within the next hour, bands 2 and 3 of AdcA progressively disappeared in favour of the fast migrating band, leading to a migration pattern at 120 min after stimulation comparable to that observed in untreated cells. The extent and duration of each phase was dose-dependent as illustrated on Figure 1B on KAx-3 subjected to increasing concentrations of sorbitol (50 to $200 \mathrm{mM}$ ). Treatment of the cells with a second sorbitolmediated osmotic challenge $180 \mathrm{~min}$ after the first shock resulted in a new round of AdcA response (yet not as efficient), indicating that the cells were able to reactivate the pathway(s) governing AdcA response and therefore, at least partially, recover from stress (Figure 1C).

To identify the type of modification(s) responsible for AdcA shift, protein samples were treated with calf intestine phosphatase (CIP) to test the possibility of phosphorylation. As shown in Figure 1D, CIP treatment of protein samples from sorbitol-stressed cells harbouring bands 2 and 3 restored the band 1-migration pattern of unstimulated cells (fast migrating species) while buffer alone had no effect. Similar results were obtained with $\lambda$-phosphatase (not shown). These data strongly suggest that AdcA is modified by multiple phosphorylations when subjected to hyperosmotic stress. The dephosphorylation protocol we used includes a step of sample concentration by precipitation in trichloroacetic acid. Such conditions are unlikely to maintain the acid-labile phosphorylation of residues such as histidine and aspartate. Because the use of several phospho-tyrosine specific antibodies failed to detect any phospho-AdcA in an AdcA immunoprecipitate, we currently favor the hypothesis of a phosphorylation on serine/threonine residues.

\section{AdcA is modified in response to various stresses}

To determine whether AdcA response to sorbitol reflected a general sensitivity to osmostresses, other hyperosmotic agents were tested. As shown on Figure 1E, 200 mOsm concentrations of glucose, glycerol or $\mathrm{NaCl}$ were all capable of triggering AdcA phosphorylation. As observed for sorbitol, the effect of $\mathrm{NaCl}$ is similarly dose-dependent (not shown). Conversely, a hyposmotic shock obtained by shifting the cells from axenic medium to 5-fold diluted medium (130 mOsm to $26 \mathrm{mOsm}$ ) did not affect AdcA behaviour (Figure 1E, Hypo). To evaluate whether AdcA phosphorylation is part of a general stress response, cells were subjected to non-osmotically active stresses. AdcA responded equally well to heat shock $\left(32^{\circ} \mathrm{C}\right)$, mitochondrial uncoupler $\left(10 \mu \mathrm{M}\right.$ FCCP), oxidative stress $\left(2 \mathrm{mM} \mathrm{H}_{2} \mathrm{O}_{2}\right)$ but only weakly to a $50 \mu \mathrm{M} \mathrm{Cd}^{2+}$ treatment, indicating that AdcA is sensitive to a large variety of cell stresses 


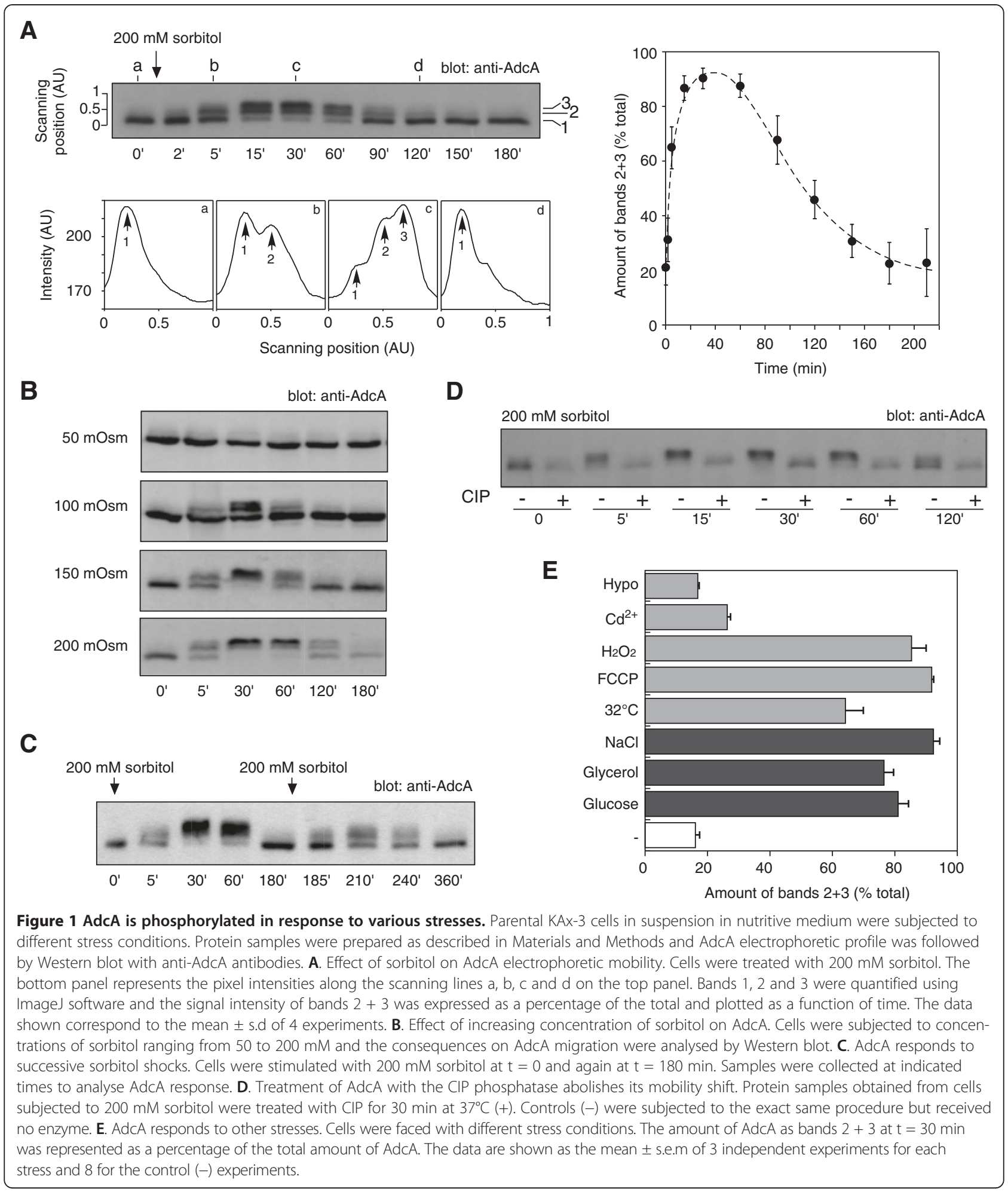

(Figure 1E). The pathways activated in response to heat shock, energetic and oxidative stresses have not been characterized in details but given our results, it is possible that they all share an effector, common to the osmostress cascade leading to AdcA phosphorylation.
AdcA is phosphorylated on the $\mathrm{N}$-terminal $\mathrm{H} \Phi$ domain Besides its central arrestin core, the adaptor protein AdcA contains a PI(3)P-binding FYVE domain in the Cterminal part and a histidine-rich triplicated region that extends the protein $\mathrm{N}$-terminally. To localize the site(s) 


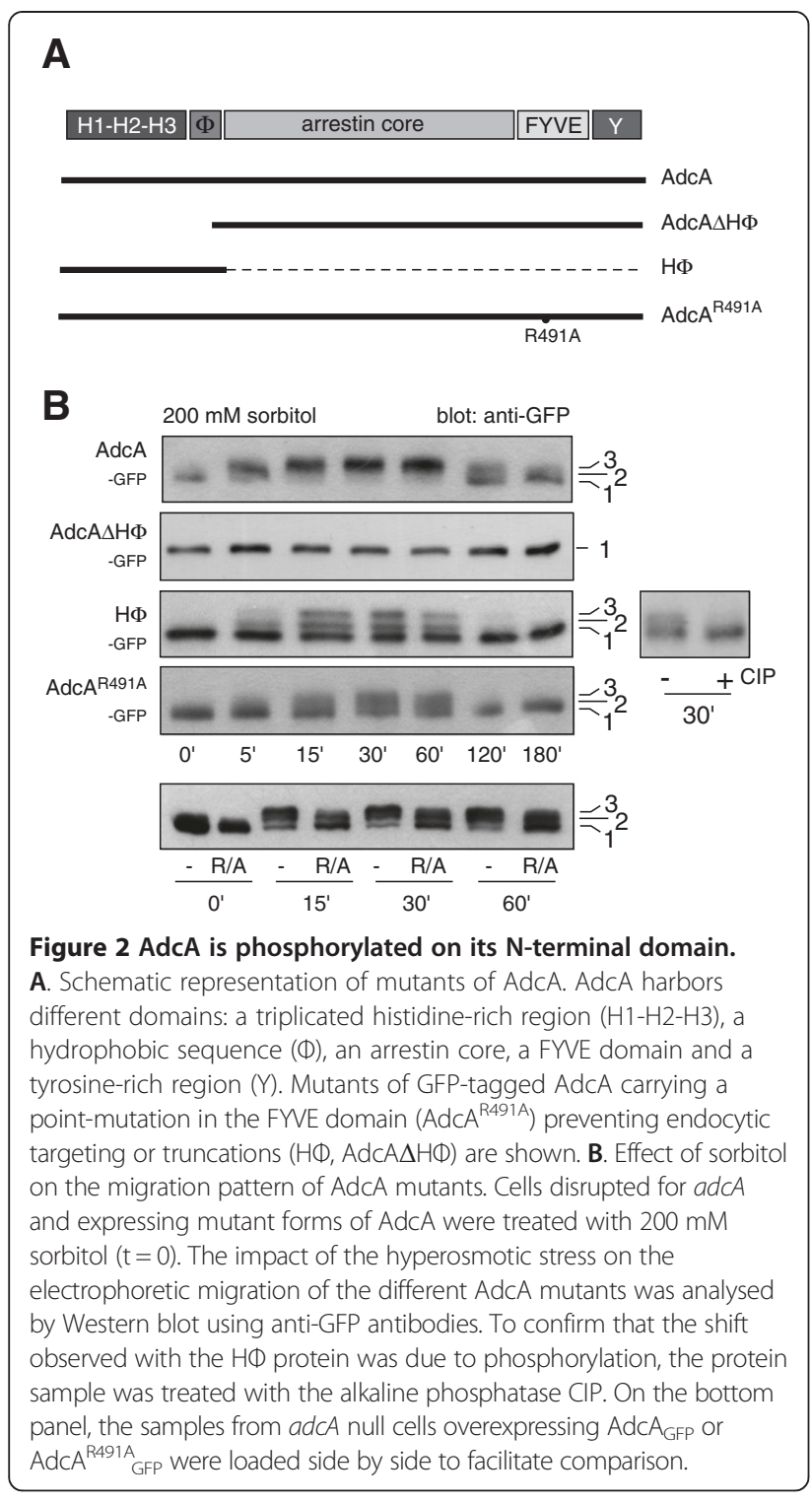

of phosphorylation, the effect of $200 \mathrm{mM}$ sorbitol was measured on truncated forms of AdcA, AdcA $\Delta \mathrm{H} \Phi_{\mathrm{GFP}}$ and the $\mathrm{H} \Phi_{\mathrm{GFP}}$ expressed in both a KAx-3 and $a d c A$ null background to exclude a possible interference of the endogenous AdcA (Figure 2A). The construct AdcA $\mathrm{A}_{\mathrm{GFP}}$ was used as a control. A mobility shift induced by sorbitol with the appearance of two slower migrating forms and reversed by CIP treatment was observed for the $\mathrm{H} \Phi_{\mathrm{GFP}}$ construct in both cell backgrounds but was completely lost in AdcA $\Delta \mathrm{H} \Phi_{\mathrm{GFB}}$, indicating that the $\mathrm{N}$ terminal domain of AdcA contains the phosphorylation sites critical for the shift and the appropriate context for the recruitment of the required kinase and phosphatase (Figure 2B, not shown for the KAx-3 background). Nevertheless, even though the kinetics of phosphorylation of the $H \Phi_{\mathrm{GFP}}$ protein is the same as that of endogenous AdcA and AdcA $_{\mathrm{GFB}}$ the extent of phosphorylation is different with roughly $50 \pm 4 \%(\mathrm{n}=3)$ of total $H \Phi_{\text {GFP }}$ in the bands $2+3$ at 30 min post-shock versus $81 \pm 8 \%(n=3)$ for the full-length AdcA $_{\text {GFP }}$ protein. This difference could possibly be attributed to the higher level of expression of $\mathrm{H} \Phi_{\mathrm{GFP}}$ and a limiting level of kinase activity. Alternatively, if the subcellular localisation of $\mathrm{H} \Phi_{\mathrm{GFP}}$ were distinct from that of AdcA, this could also interfere with the phosphorylation efficiency. Indeed, while AdcA is massively associated with the endocytic apparatus, the $\mathrm{H} \Phi$ construct is mostly found in the cytosol [16]. Another mutant of AdcA, AdcA ${ }_{\text {GFB }}^{\text {R491A }}$ that is unable to bind PI(3)P, fails to localize to the endocytic compartments [16]. Similarly to $\mathrm{H} \Phi_{\mathrm{GFP}}$ AdcA ${ }_{\text {GFP }}^{\mathrm{R} 491 \mathrm{~A}}$ phosphorylation is partial, despite an expression level comparable to that of $\mathrm{AdcA}_{\mathrm{GFB}}$ supporting a correlation between the endocytic localization and the phosphorylation level of the protein rather than a phosphorylation level mirroring the expression level of the constructs (Figure 2A, B).

The HФ domain of AdcA contains 31 serines/threonines (and 2 tyrosine residues), precluding a systematic pointmutation approach to test their relative contribution to the phosphorylation pattern. Attempts to map the phosphorylated site(s) by mass spectrometry on the immunoprecipitated $H \Phi_{\text {GFP }}$ protein were so far unsuccessful.

\section{Vegetative cells and starved cells confronted by hypertonicity share common features}

In nutritive conditions, Dictyostelium cells multiply actively as single cells (vegetative state) and nutrient depletion triggers a developmental program leading to a multicellular structure containing starvation-resistant spores. In Dictyostelium, the consequences of a hyperosmotic stress have been well characterized on cells starved for a 1-4 h period of time and several effectors of the osmoresponse have been identified [18-26]. Hyperosmotic conditions trigger a variety of responses, such as cell shrinkage, cytoskeleton rearrangement and actin/myosin phosphorylation. High osmolarity responses include a rapid and transient accumulation of intracellular cAMP and of intracellular cGMP that functions, in parallel to $\mathrm{Ca}^{2+}$-based pathways, to activate the stress-activated transcription factor STATc [19,21,26,27].

To position AdcA in the osmostress-response signaling network, we first compared the stress response of growing KAx-3 cells to that of starving cells. When treated with $200 \mathrm{mM}$ sorbitol, vegetative cells rounded up and shrunk rapidly, stopped their random motility and detached progressively from the substratum (Figure 3A, Additional file 1: Movie 1). Actin redistributed uniformly around the cell periphery as observed for starving cells, within a few minutes after sorbitol addition (Figure 3B). A transient Tyr-phosphorylation of actin was also detectable $15 \mathrm{~min}$ 


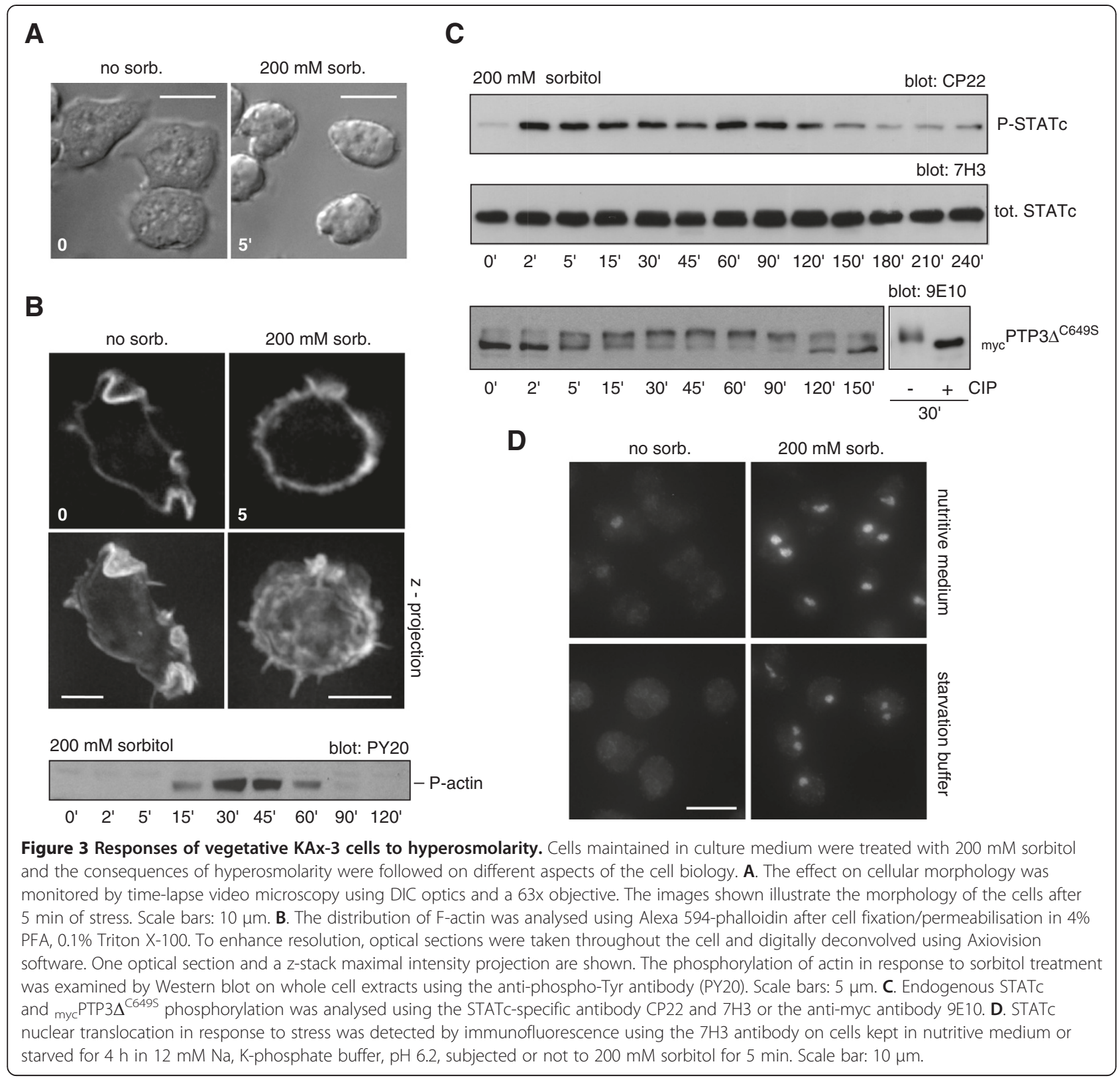

after the shock with a peak around 30 min (Figure 3B). One participant in the osmostress response in starving cells, STATc, was also Tyr ${ }^{922}$ phosphorylated in our conditions within minutes following application of the osmotic stress (Figure 3C). As observed for AdcA and actin, this phosphorylation is transitory as a slow dephosphorylation proceeded past 90 min post-shock. The osmostress activation of the transcription factor STATc was shown to depend on a dual regulation involving a not yet identified tyrosine-kinase and the tyrosine-phosphatase PTP3, the activity of which is inhibited by phosphorylation on Ser/Thr residues $[19,28]$. As shown on Figure 3C, the protein ${ }_{\text {myc }}$ PTP3 $\Delta^{\mathrm{C} 649 \mathrm{~S}}$, used as a reporter of PTP3 behaviour [27], was also transiently phosphorylated (as validated by the CIP effect), thereby likely contributing to STATc activation. STATc phosphorylation was accompanied by its translocation into the nucleus (Figure 3D). Noteworthy, while STATc is massively cytosolic in early developing cells, we could detect some staining in the nucleus of growing cells suggesting a basal level of activation of the transcription factor in vegetative conditions. This is supported by the low but detectable basal level of phospho-STATc observed in growing cells (Figure 3C). 


\section{Efficient AdcA phosphorylation requires pathways other than the DokA and cGMP-dependent osmostress pathways}

We next examined whether some of the secondary messengers described to function in the osmoresponse of starving cells (i.e. $\mathrm{Ca}^{2+}$ and cyclic nucleotides) operate to trigger AdcA stress-induced response. In hyperosmotically-stressed starving cells, a peak of cAMP is detected, due to the activation of the histidine kinase DokA and the subsequent transient inhibition of the cytosolic cAMP phosphodiesterase RegA [21,24]. The addition of the membrane-permeable analogue 8-Br-cAMP, used to mimic an increase in the cAMP cytosolic concentration, failed to activate AdcA in growing cells (Figure 4A). As such treatment only triggered a low level of STATc phosphorylation (used as a control), the effect of 8-BrcAMP was also tested on $4 \mathrm{~h}$ starved cells, conditions known to induce a substantial response of the transcriptional factor ([18], Figure 4A). While sorbitol treatment also triggered the phosphorylation of AdcA in starved cells (yet not as efficiently as in vegetative cells), no activation of the AdcA response was observed with 8-Br-cAMP (Figure 4A). In agreement with these data, the $\operatorname{dok} A$ null mutation maintained the sorbitol-inducible phosphorylation of AdcA (Figure 4B). DokA being poorly expressed in vegetative cells, the experiments were also conducted on starved cells showing that the absence of $\operatorname{dok} A \operatorname{did}$ not alter AdcA phosphorylation profile (Figure 4B). A DokAcAMP pathway is therefore unlikely to participate to AdcA phosphorylation.

We next tested the possible contribution of cGMP- and calcium-dependent pathways. While treatment of cells with 8-Br-cGMP efficiently activated STATc in vegetative cells, its effect on AdcA was very weak (Figure 4C). Dictyostelium encodes two characterized guanylate cyclases, the soluble hyperosmotic stress-inducible protein sGC and the membrane-associated GCA protein [23]. The deletion of $g c a / s g c$ has been shown to result in a complete loss of detectable guanylate cyclase activity in $1 \mathrm{~h}$-starved cells subjected to $300 \mathrm{mOsm}$ challenge. Disruption of both $g c a$ and $s g c\left(g c a^{-} / s g c^{-}\right)$did not interfere with the full phosphorylation of AdcA in response to sorbitol (Figure 4D). In parallel, thapsigargin was used to induce an elevation of intracytosolic calcium. Again, this treatment caused an accumulation of phosphorylated STATc but barely induced a response from AdcA (Figure 4C). However, the addition of both thapsigargin and 8-BrcGMP together was able to produce the appearance of band 3 (Figure $4 \mathrm{C}$ ). The response was partial compared to the sorbitol effect, suggesting that these conditions did

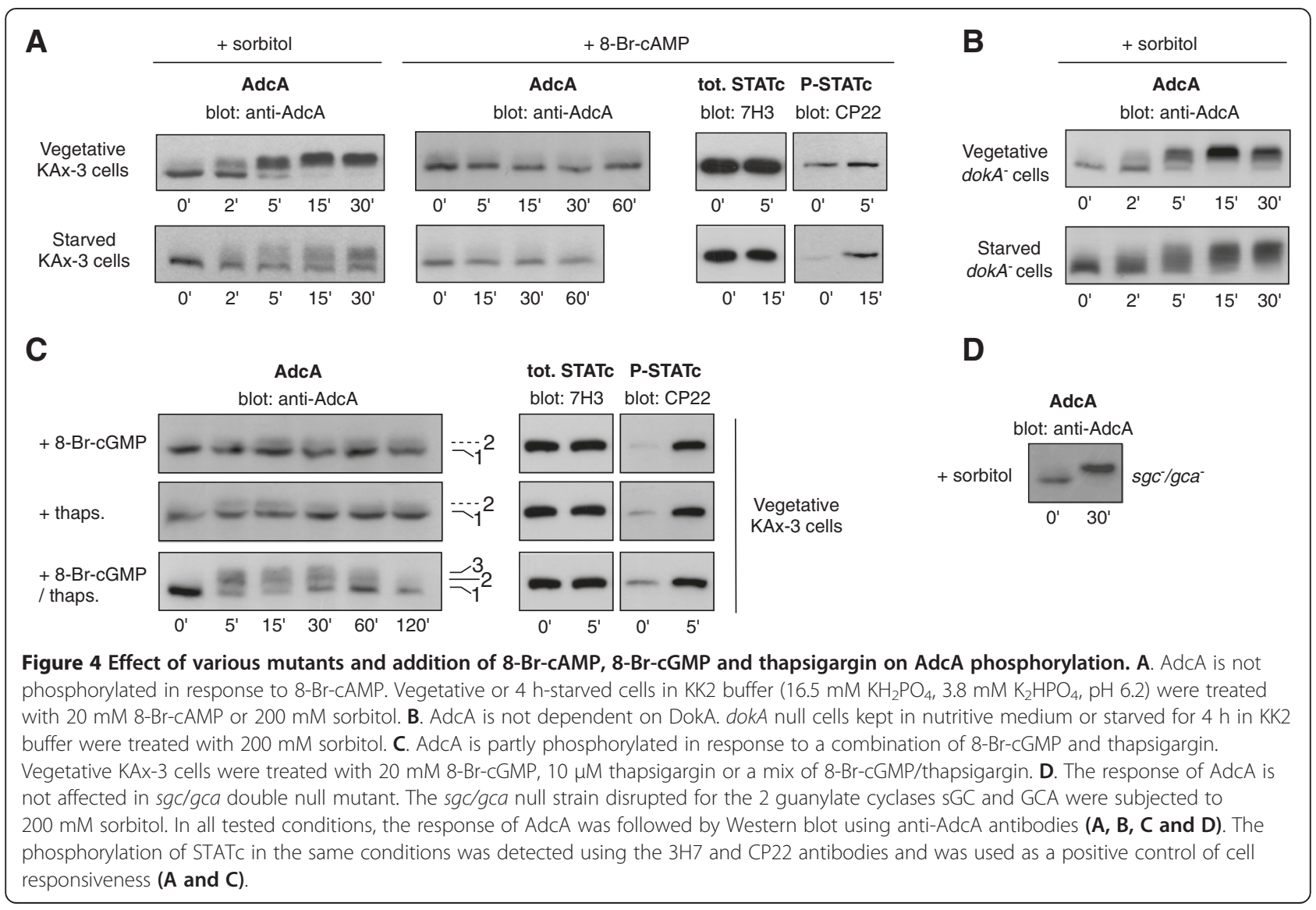


not completely mimic those generated by sorbitol. The doses used and their simultaneous addition may not be the most effective combination to trigger AdcA phosphorylation. An alternative hypothesis is that, in conditions of hyperosmotic stress, cGMP and $\mathrm{Ca}^{2+}$ - dependent pathways function in parallel to additional pathways to elicit a full AdcA response.

\section{AdcA phosphorylation is induced by a destabilization of the actin network}

All the treatments driving AdcA phosphorylation led to a rounding up of the cells, likely involving a reorganisation of the actin cytoskeleton (Figure 5A). In the case of hyperosmotic stress, a protective cortical shell of F-actin is built through a massive restructuration of the actin network (Figure 3A, [25]). This led us to test whether the sole destabilization of the actin network could trigger AdcA phosphorylation. Cells were treated with two structurally and functionally distinct actin cytoskeleton disrupting agents, cytochalasin $\mathrm{A}(10 \mu \mathrm{M})$ or latrunculin B $(5 \mu \mathrm{M})$. As shown on Figure $5 \mathrm{~B}$, these two drugs led to the activation of STATc as previously described by Araki and Williams on starved cells [29]. Cytochalasin A also induced a robust and rapid response of AdcA with the massive accumulation of band 3 , comparable to that obtained in sorbitol treated cells. Latrunculin B (Figure 5B) as well as latrunculin A (not shown) were also able to trigger AdcA phosphorylation, yet not as efficiently. Thus, actin depolymerisation is sufficient to elicit AdcA phosphorylation. Both drug families induced a delay in the dephosphorylation of AdcA, a full dephosphorylation of
AdcA being eventually obtained only with cytochalasin A. This difference between the impacts of the drugs may be due to their distinct mode of action and the consequences of the chemicals on the cell physiology. Dictyostelium cells may be able to expel cytochalasin A through multidrug resistance pumps of the plasma membrane, allowing the cell to restore the basal parameters including a dephosphorylated AdcA.

\section{AdcA phosphorylation is not dependent on ERK proteins, PKA or GbpC}

To determine the kinase(s) responsible for AdcA phosphorylation, we tested AdcA response to sorbitol in strains disrupted in candidate kinases. As expected from the absence of AdcA response upon 8-Br-cAMP addition, a deletion mutant in the PKA catalytic subunit (pkacat) was still responsive to sorbitol treatment, excluding a role for this Ser/Thr kinase (Figure 6). The small effect of 8-BrcGMP prompted us to test the cGMP-binding kinase $\mathrm{GbpC}$, an intermediate in the osmostress signaling cascade leading to STATc phosphorylation. Disruption of $g b p C$ did not alter AdcA phosphorylation kinetics (Figure 6).

In yeast and mammals, MAP kinases are key actors in the signaling pathways activated in conditions of hyperosmotic stress. In Dictyostelium, the involvement of the two MAP kinases Erk1 and Erk2 in the osmostress response has not been addressed in detail but $\mathrm{Na}$ and colleagues [17] suggested the implication of a MAPK dependent pathway. Interestingly, the MAP kinase kinase MEK1 is hyperphosphorylated in developing cells subjected to high osmolarity conditions, with kinetics similar to that of
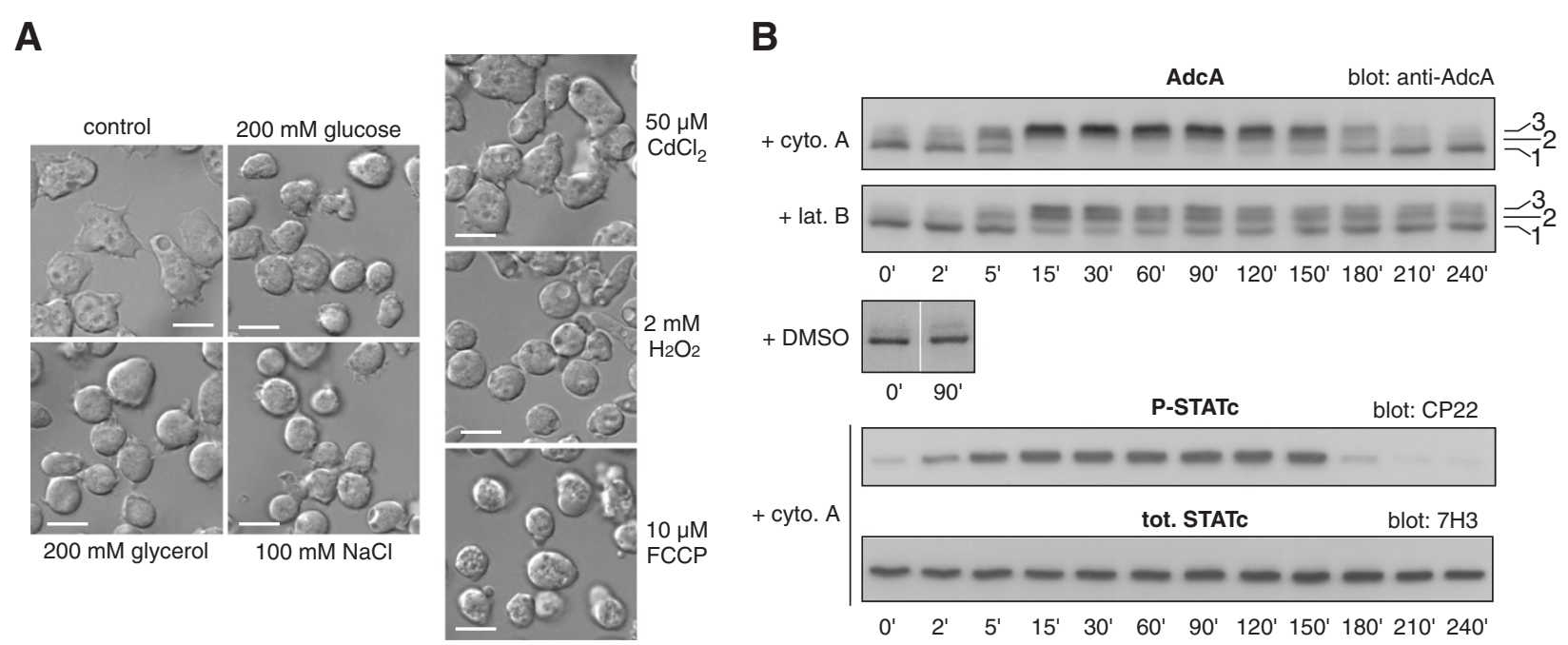

Figure 5 Involvement of the actin cytoskeleton in AdcA response. A. Morphological changes induced by various stresses. Cells in nutritive medium were let to adhere for $1 \mathrm{~h}$ on glass coverslips and were treated with $200 \mathrm{mOsm}$ glucose, glycerol or NaCl, 2 mM H $\mathrm{H}_{2}, 10 \mu \mathrm{M}$ FCCP

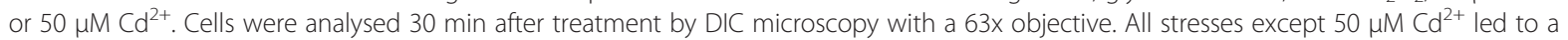
rounding up of the cells. Scale bar: $10 \mu \mathrm{m}$. B. Actin depolymerisation induces AdcA phosphorylation. KAx-3 cells were subjected to $10 \mu \mathrm{M}$ cytochalasin A or $5 \mu \mathrm{M}$ latrunculin B (addition at $\mathrm{t}=0$ ) and the impact on AdcA and STATc was followed as described above. The control cells received DMSO alone. 


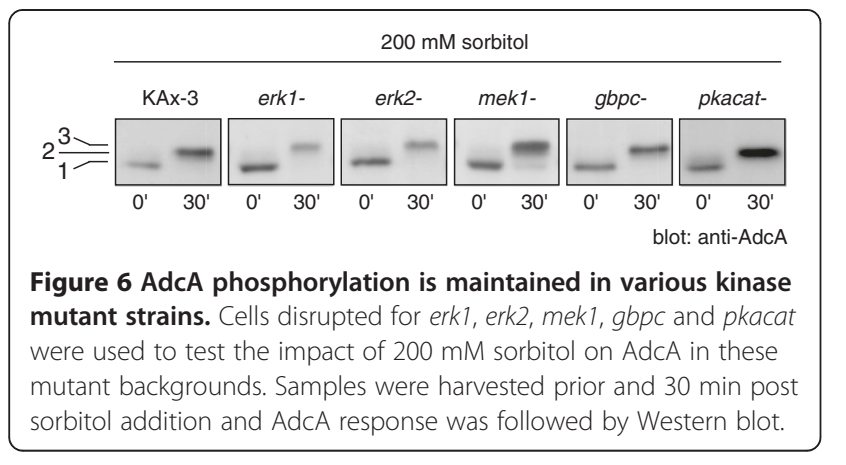

STATc [30]. Therefore, the phosphorylation status of AdcA was analysed in erk1, erk2 and mek1 null mutants (Figure 6). None of the mutations affected AdcA phosphorylation, an observation not in favor of a role for these kinases in the AdcA response.

\section{AdcA dephosphorylation is under the partial control of STATC}

Given that both AdcA and STATc responded to similar stresses (our present data; [18]), we examined the possibility of any functional link between these two targets of the osmostress. In a previous work, an $a d c A$ null strain was generated by interruption of the coding sequence by a blasticidine resistance cassette [16]. The deletion of $a d c A$ has no noticeable effect on growth and endocytosis (as measured by uptake of FITC-dextran or latex beads) (D. Guetta, GK and LA, unpublished observations). We first tested the impact of this disruption on STATc activation. As shown in Figure 7A, the absence of $a d c A$ did not affect STATc's tyrosine phosphorylation/dephosphorylation when compared to KAx-3 or its translocation to the nucleus, indicating that AdcA is not an essential intermediate in the pathway controlling STATc response.

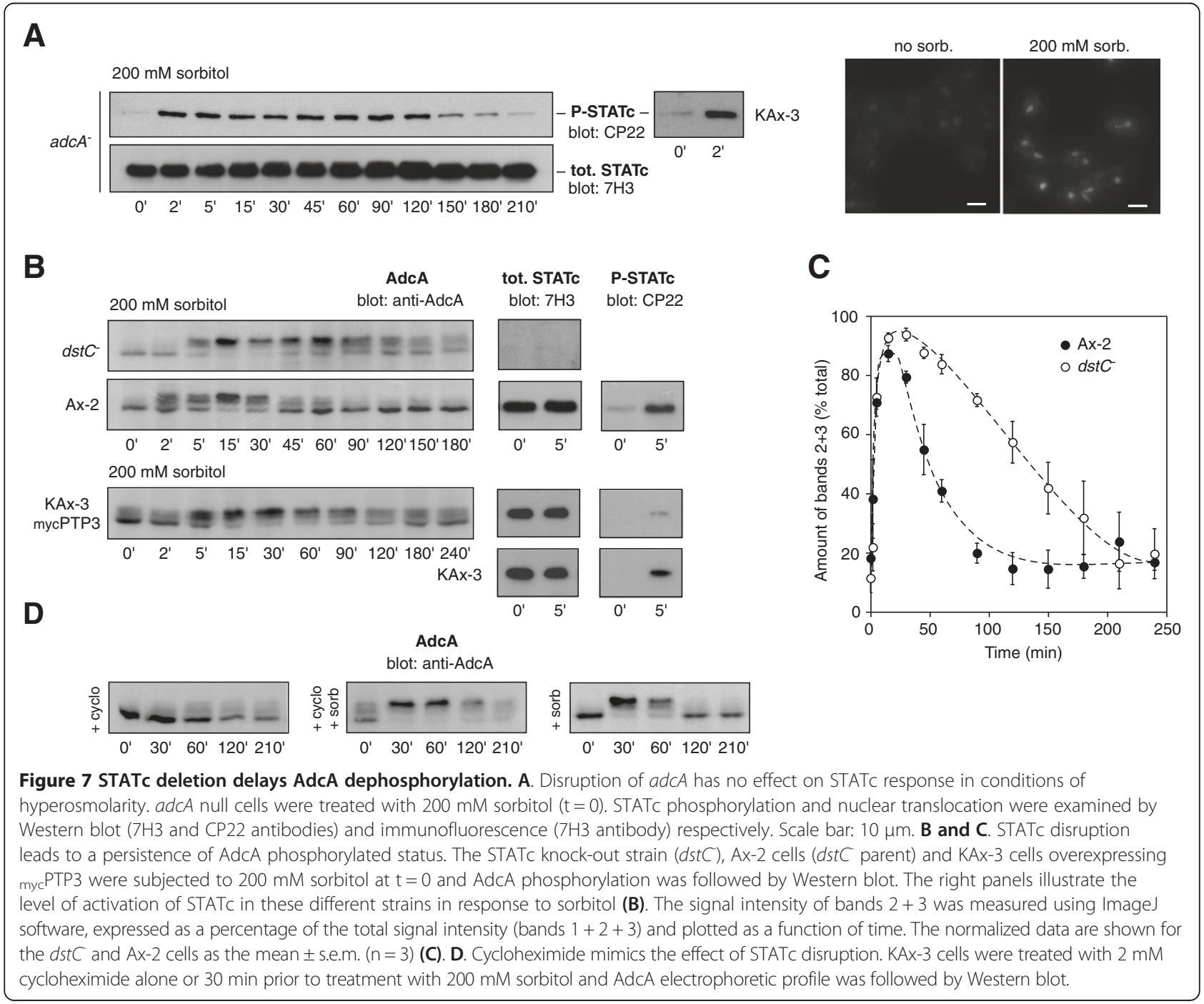


Conversely, the $d s t C$ deletion (statc null strain, Ax-2 background) affected the phosphorylation status of AdcA. In the two dst $\mathrm{C}^{-}$and Ax-2 strains, the phosphorylation peak was similarly attained around $30 \mathrm{~min}$ post sorbitol stimulation but then, in the $d s t C$ mutant, the protein remained phosphorylated for an extended period of time as evidenced by the massive amount of band 3 still present at $150 \mathrm{~min}\left(42 \pm 9 \%\right.$ in $d s t \mathrm{C}^{-}$vs $14 \pm 6 \%$ in $\left.\mathrm{Ax}-2\right)$ (Figure $7 \mathrm{~B}$ and $\mathrm{C}$ ). To further investigate a role for STATc in AdcA dephosphorylation, we repeated the same experiment in KAx-3 cells expressing various forms of PTP3 [31]. The tyrosine phosphatase PTP3 is responsible for the dephosphorylation of STATc [28]. Accordingly, the constitutive overexpression of PTP3 leads to a reduced STATc activation while overexpression of a dominant negative form of PTP3 mutated in the catalytic cysteine residue ${ }_{\text {myc }}$ PTP3 $\Delta^{\mathrm{C} 649 \mathrm{~S}}$ ) leads to a constitutively active STATc [28]. As shown on Figure 7B, exposing $\mathrm{KAx}-3$ overexpressing myc PTP3 to $200 \mathrm{mM}$ sorbitol led to a response of AdcA that resembles that observed in the $d s t C$ null strain with a persistence of AdcA phosphorylation, several hours after shock (Figure 7B). Such result suggests a role for STATc transcriptional activity in AdcA dephosphorylation. This was further supported by experiments using cycloheximide, a general protein synthesis inhibitor. While $2 \mathrm{mM}$ cycloheximide by itself had only a slight effect on AdcA (possibly due to the generation of a situation of stress after long exposure to the inhibitor), pre-treatment of KAx-3 cells with cycloheximide, for 30 min prior sorbitol addition significantly slowed down AdcA dephosphorylation with persistence of band 3 for the next $180 \mathrm{~min}$ (Figure 7D), suggesting the requirement of protein neosynthesis for dephosphorylation to occur. In KAx-3 cells overexpressing myc PTP3 $\Delta^{\mathrm{C} 649 \mathrm{~S}}$ however, the phosphorylation of AdcA was not noticeably affected despite a constitutive activation of STATc (not shown). Taken together, the data support a functional link between STATc activity and AdcA dephosphorylation. However, while STATc could very well control the expression of a component of the AdcA dephosphorylation pathway, an additional level of regulation possibly acting on the balance between the activity of the AdcA-specific kinase and that of its phosphatase must be invoked to account for the absence of effect of constitutively activated STATc.

\section{Impact of dstC and adcA disruption on cell resistance to stress}

We next undertook a characterization of the cell behaviour at the time of AdcA dephosphorylation. When subjected to a stress of $200 \mathrm{mM}$ sorbitol, the cell rounding and actin rearrangement induced within the first minutes after shock were transitory. As illustrated on Figure 8A, cells adapted progressively to their new environment and regained a partly adherent and motile behaviour around 90 min following the onset of osmotic stress. Pintsch and colleagues described that hyperosmolarity rapidly blocked vesicular trafficking and macropinocytosis with a fragmentation of the endocytic pathway [22]. In agreement with that observation, while localized on large size macropinosomes in the absence of stress, AdcA was found associated to small size structures compatible with a partially fragmented endocytic network in sorbitol-treated cells (Figure 8B, [16]). Our data also confirmed the arrest of the endocytic activity as shown by the inhibition of the internalization of the fluid-phase marker FITC-dextran within the first minutes following the addition of $200 \mathrm{mM}$ sorbitol (Figure 8B). However, this arrest is transient. Indeed, past $90 \mathrm{~min}$ of stress and in parallel to cell spreading and recovery of motility, $\mathrm{KAx}-3$ cells had resumed some macropinocytic activity (Figure 8B, $200 \mathrm{mM}$ sorb.). Past the adaptation phase, AdcA localization on large size endocytic vesicles was again visible (Figure 8B, c and c'). Lower concentrations of sorbitol $(100 \mathrm{mM})$ allowed a faster cell recovery assessed by endocytosis measurements while higher, yet not lethal, concentrations (400 mM) prohibited adaptation at least during a $5 \mathrm{~h}$ time window. In all cases, recovery of the cells temporally correlated with AdcA dephosphorylation (Figure 1A, B and Figure 8B). We reported above that a dephosphorylation of AdcA also occurred in cells maintained in the presence of cytochala$\sin \mathrm{A}$. In these conditions, an endocytic activity was eventually restored by 180 min post cytochalasin A addition, possibly due to the pumping of cytochalasin A outside of the cells via MDRs and the subsequent restructuration of a functional actin cytoskeleton. In such cells, the regain of endocytic activity also paralleled AdcA dephosphorylation (Figures 5B, 8C).

We next asked whether $\operatorname{adcA}$ disruption modified cell resistance to stress and recovery. To test a possible contribution of AdcA to the osmoresponse, parental KAx-3 and $a d c A$ null cells were first subjected to increasing concentrations of sorbitol (100 to $400 \mathrm{mM}$ ) and cell growth was followed on a $96 \mathrm{~h}$ period of time. Addition of sorbitol affected cellular growth in a dose-dependent manner but similarly in $a d c A$ null and control cells suggesting that $a d c A$ deletion had no significant consequences on survival in hyperosmotic conditions (not shown). Analysis of the $a d c A$ null cell response in greater detail within the first four hours following a $200 \mathrm{mM}$ sorbitol treatment confirmed that the absence of AdcA has no impact on cell recovery as indicated by the macroscopic morphological changes (not shown) and restoration of endocytosis within the same time frame as for KAx-3 cells (Figure 7C).

Given the impact of the $d s t C$ null mutation on AdcA dephosphorylation, we analysed the effect of the absence of STATc activity on cell adaptation to stress. Data from Araki and colleagues [18] established that STATc is not 


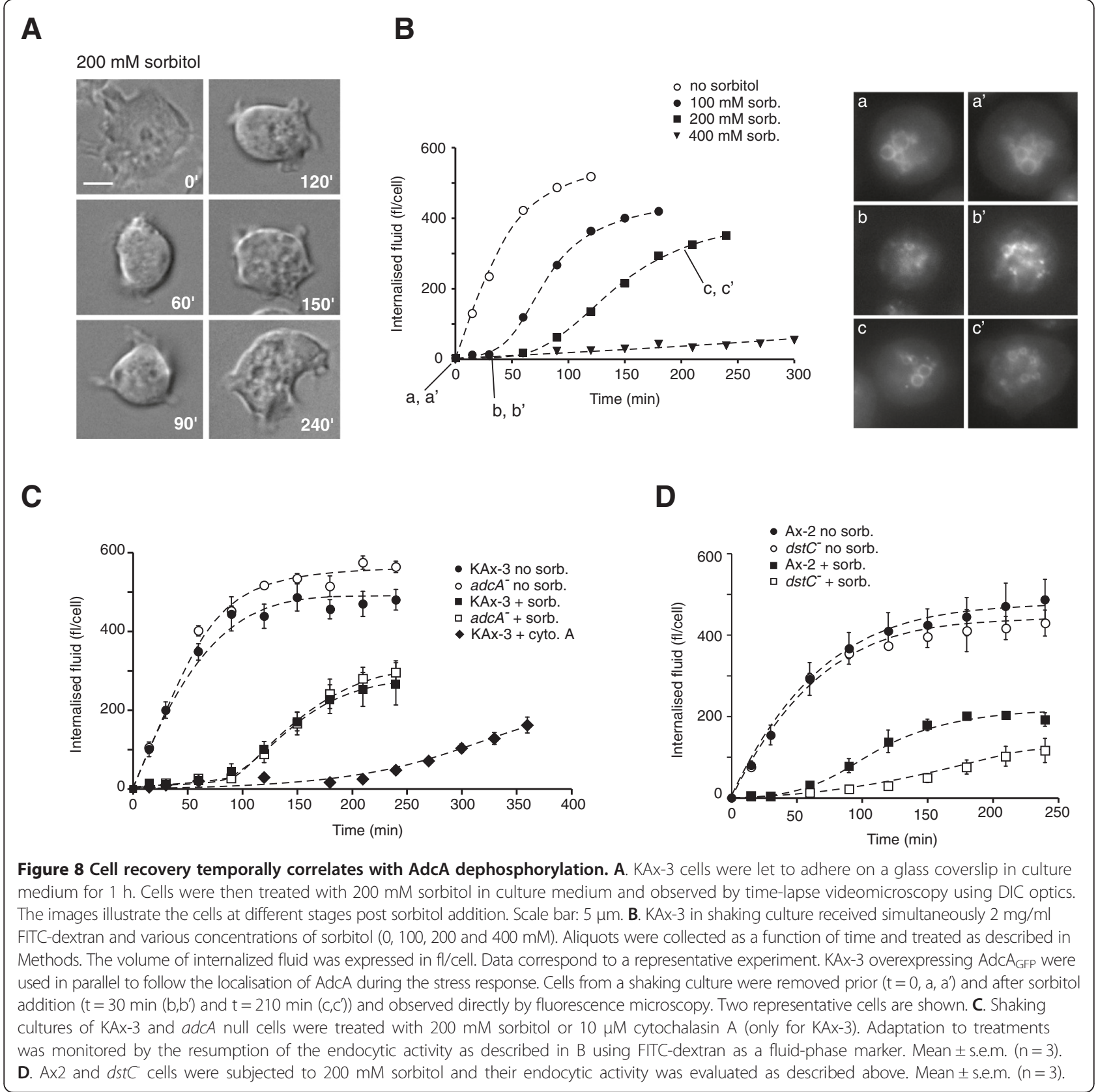

essential for stress resistance as assayed by regrowth on Klebsiella after 2 h-exposure to $200 \mathrm{mM}$ sorbitol. We tested here, by a less stringent discriminator, the capacity of the $d s t C$ null cells to restore some endocytic activity within the first hours after the onset of shock. As shown in Figure 8D, while Ax-2 cells regained an endocytic behaviour within 50-60 min post shock, the absence of STATc led to a delay in recovery, comparable to the delay observed in the kinetics of AdcA dephosphorylation.

\section{Discussion}

In the present study, we provide evidence that AdcA, one of the amoebal arrestin-related proteins, is a response element to a number of stresses in growing cells. Using a hyperosmotic shock induced by sorbitol as a paradigm, we showed that the sensing of the shock by vegetative amoebae is accompanied not only by the phosphorylation of the known actors of the osmostress response, the tyrosine phosphatase PTP3 and the transcription factor STATc but also by a multi- 
phosphorylation of AdcA, most probably on serines/ threonines. Adaptation of the cells to the osmostress situation temporally correlates with the dephosphorylation of AdcA.

Given that hyperosmolarity evokes AdcA phosphorylation, we tried to position AdcA relatively to known mediators of the osmoresponse. In response to the osmotic shock, vegetative cells like starving cells shrink rapidly and modify their cortical actin. In starving cells, distinct pathways have been described that contribute to the cell response in conditions of high osmolarity: i) cGMP- and $\mathrm{Ca}^{2+}$-dependent pathways involved in the cytoskeletal remodelling and the activation of the transcription factor STATc $[19,26,32]$ and ii) a two-component system dependent pathway including the histidine kinase DokA, the intermediate histidine phosphotransfer protein RdeA and the cAMP phosphodiesterase RegA [21,24]. Whether a signaling cascade involving MAPKs is also active as described in yeast and mammals is still unclear but has been suggested by $\mathrm{Na}$ and colleagues [17]. Using known inducers of these signaling cascades or null mutants in some of their respective effectors, our data indicate that AdcA phosphorylation results from the integration of signals arising from multiple pathways including cGMP and $\mathrm{Ca}^{2+}$-dependent ones. Interestingly, remodelling of the actin cytoskeleton by F-actin disrupting drugs is an efficient inducer of AdcA phosphorylation. Though AdcA and STATc responses are both elicited by common stresses including F-actin destabilization (this work, [18,29]), an early branching off of the pathways leading to the phosphorylation of AdcA and STATc is therefore likely to occur (Figure 9). In the case of STATc, the cGMP effect is mediated by the Roco kinase $\mathrm{GbpC}$, a regulator of the cytoskeletal network. This pathway is not essential for AdcA response. The partial effect of the concomitant increase of cGMP and $\mathrm{Ca}^{2+}$ on AdcA phosphorylation therefore needs to imply other targets for the secondary messenger cGMP as well as other intermediates, possibly involved in the remodelling of the actin network.

The identification of the kinase responsible for AdcA's phosphorylation would clearly help positioning AdcA in the signaling cascade. In addition to $\mathrm{GbpC}$, our data disqualified PKA, Erk1, Erk2 and MEK1 as key kinases in AdcA phosphorylation. The amoebal kinome includes 255 kinases, with 155 putative Ser/Thr-directed kinases [33]. As AdcA is associated with the PI(3)P-enriched endosomal membrane, we could expect its kinase to be membrane-associated, all the more as soluble mutants of AdcA, e.g. the HФ domain or the $\operatorname{AdcA}^{\text {R491A }}$ construct, were less efficiently phosphorylated than AdcA. Alternatively, the hypothesis that folding of the soluble domains of AdcA and of $\operatorname{AdcA}^{\mathrm{R} 491 \mathrm{~A}}$ are different enough from that of AdcA to decrease the affinity for the kinase would perfectly accommodate a soluble kinase. It is thus

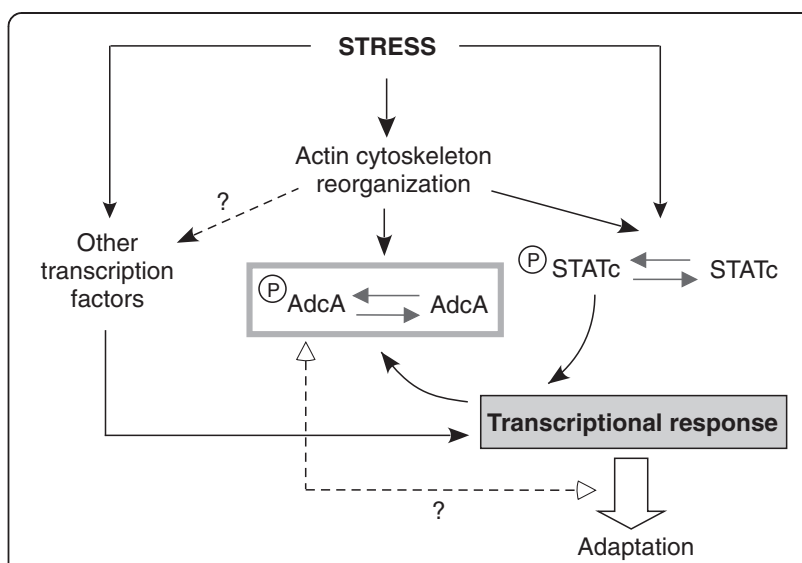

Figure $9 \mathrm{~A}$ model for AdcA in the stress response. The model proposes that hyperosmolarity, as various other stresses, leads to a reorganization of the cytoskeletal network, and the consequent phosphorylation of response elements including STATc and AdcA, possibly through the activation of a membrane sensor. STATC participates to the cellular transcriptional response triggered by stress. AdcA dephosphorylation is in part dependent on STATC activity and correlates with recovery of the cells from stress. Whether AdcA phosphorylation allows the activation or the inhibition of AdcA is not known, but this phosphorylation or the following dephosphorylation may be required for a full cell recovery.

impossible at this stage to make an informed guess as to which kinase is responsible for AdcA's phosphorylation. In mild conditions of stress (100-200 mM sorbitol), AdcA phosphorylation is transient and its dephosphorylation is partly dependent on STATc. Given the transcriptional activity of STATc, a simple hypothesis is that STATc regulates the expression of a mediator of AdcA dephosphorylation such as the phosphatase itself or a regulator of the enzyme. $\mathrm{Na}$ and colleagues established by means of DNA microarray profiling the transcriptional profile of vegetative cells challenged with high sorbitol, and, among the differentially regulated genes, those that were dependent on the presence of STATc [17]. The list of osmostressinduced STATc-regulated genes contains only one protein phosphatase, DDB_G0274153. DDB_G0274153 encodes a putative serine-threonine protein phosphatase $2 \mathrm{C}$ expressed in vegetative conditions. This phosphatase may regulate AdcA phosphorylation and will receive a particular attention. However, AdcA is phosphorylated on multiple sites, STATc inactive mutants permit a partial dephosphorylation of AdcA and the constitutive activation of STATc is mostly silent while a reduction of the extent of AdcA phosphorylation would be expected. The regulation of AdcA response is thus likely to be more complex and involve parallel and complementary pathways in both the phosphorylation and the dephosphorylation steps.

In higher eukaryotes, $\beta$-arrestins are recruited to GPCRs stimulated by ligand binding. This leads to the 
uncoupling of the receptors from their associated G proteins, the arrest of downstream signaling and the internalization of some of these GPCRs in clathrin-coated vesicles through the interaction of the arrestins with components of the endocytic machinery and the activation of signaling cascades from the endosomal platform $[4,34]$. In yeast, more recent data have established that $\alpha$-arrestin-dependent pathways are activated in response to stresses and changes in nutritive conditions or ambient $\mathrm{pH}$, triggering the trafficking of plasma membrane permeases. Targets include the general amino acid permease Gap1 (and the $\alpha$-arrestins Bul1, Bul2), the arginine transporter Can1 (ART1), the lactate permease Jen1 (Rod1), the manganese transporter Smf1 (ART2, ART8) or the 7-transmembrane pH sensor Rim21 (ART9/ Rim8) [8-13,35]. Arrestins and arrestin-like proteins are regulated by phosphorylation. In the absence of ligand stimulation, $\beta$-arrestins are cytosolic in an inactive, phosphorylated oligomeric form and their recruitment to a phosphorylated GPCR requires their dephosphorylation [36-39]. When the nutrient source is restricted, the phosphorylated forms of $\alpha$-arrestins are maintained in a complex with the scaffolding protein 14-3-3 [10,12]. The provision of nutrients activates their dephosphorylation, allowing them to target the E3 ubiquitin ligase Rsp5 on specific cargoes, thereby promoting cargo downregulation $[8,10,12]$. How does the phosphorylation/dephosphorylation response of AdcA to stress compare to that experienced by $\alpha$-and $\beta$-arrestins? We have shown that hyperosmotic stresses, as well as oxidative or heat shock conditions trigger a massive phosphorylation of the pool of AdcA. Whether this phosphorylation leads to the activation or the inactivation of AdcA is not yet established as the exact role of AdcA is currently unknown and none of AdcA membrane targets has been identified. The limited consequences of $a d c A$ deletion on cell response to hyperosmolarity would rather argue against a role for AdcA as an actor of the osmostress response. However, to provide a definite conclusion on the significance of AdcA phosphorylation in the stress context, identification of the phospho-sites and the subsequent construction of phospho-mimicking and non-phosphorylable mutants of the protein will be essential. We showed that, in various contexts of stress affecting cell morphology and endocytic activity, AdcA response consistently correlates with cell behaviour. AdcA being a protagonist of the endocytic pathway, its phosphorylation could modify its function and interfere with the regulation and fate of some key membrane targets (e.g. ion transporters) involved in the stress response. While the absence of AdcA may be silent, its phosphorylated and/or dephosphorylated form could be necessary intermediates for an optimal response and reaching of a novel homeostasis (Figure 9) if one of these forms was to act as an inhibitor in the response.
The responsiveness of AdcA to various types of stress raises the question of the nature of the cellular trigger common to all the stresses, and able to elicit AdcA phosphorylation. In eukaryotes, defects of the cytoskeleton are one of the major damages observed in response to stress conditions. In Dictyostelium, two observations support a role for the cytoskeleton as a "stress transducer", common to all stress conditions: (i) stressors described to trigger AdcA phosphorylation all alter the cellular morphology and (ii) cytochalasin A as well as latrunculins are able to induce AdcA response in the absence of any other stressor. Given the intricate network of interactions between cytoskeletal elements and transmembrane or membrane-associated proteins, remodelling of the actin cytoskeleton could directly contribute to the activation/inhibition of signaling cascades and the transmission of signals to downstream stress-response effectors, among which AdcA kinase.

\section{Conclusions}

In the telluric amoebae Dictyostelium, hypertonicity triggers immediate morphological changes with remodelling of the cytoskeleton and activation of a transcriptional response affecting the expression of hundreds genes. Our data identified a novel target of the osmostress response, the arrestin-related protein AdcA, the regulation of which by a phosphorylation/ dephosphorylation cycle might allow an optimal response of cells under stress.

\section{Methods}

\section{Strains and cell culture conditions}

Except when mentioned, the experiments were conducted on the Dictyostelium discoideum parental strain KAx-3. The null cells $g b p C^{-}$(DBS0302680), mek1 (DBS0236541), pkacat (DBS0236783) and $\mathrm{gca}^{-} / \mathrm{sgc}^{-}$ (DBS0236000) were obtained from the Dicty Stock Center. The erk1 and erk2 null cells were kindly provided by J. Hadwiger and the $\operatorname{dok} A^{-}$mutant was obtained from S. Schuster. The $a d c A^{-}$(parent $\mathrm{KAx}-3$, bs ${ }^{\mathrm{R}}$ ) and strains overexpressing AdcA constructs $\left(\mathrm{G} 418^{\mathrm{R}}\right)$ $\left(\mathrm{KAx}-3 /\right.$ AdcA $_{\text {myc }}, \mathrm{KAx}-3 / \mathrm{AdcA}_{\mathrm{GFB}} \mathrm{KAx}-3 / \mathrm{AdcA} \Delta \mathrm{H} \Phi_{\mathrm{GFB}}$ $\mathrm{KAx}-3 / \mathrm{H}_{\mathrm{GFB}} \quad \mathrm{KAx}-3 / \mathrm{AdcA}_{\mathrm{GFB}}^{\mathrm{R} 491 \mathrm{~A}}$ adc $A^{-} / \mathrm{AdcA}_{\mathrm{GFP}}$ $a d c A^{-} / \operatorname{AdcA} \triangle \mathrm{H}_{\mathrm{GFB}} a d c A^{-} / \mathrm{H}_{\mathrm{GFB}}$ adc $\left.A^{-} / \operatorname{AdcA}_{\mathrm{GFP}}^{\mathrm{R} 491 \mathrm{~A}}\right)$ were described previously [16]. The $d s t C$ (parent $\mathrm{Ax}-2$, hyg $^{\mathrm{R}}$ ) was described earlier [18]. KAx-3/myc PTP3 and $\mathrm{KAx}-3 /{ }_{\text {myc }} \mathrm{PTP} 3 \Delta^{\mathrm{C} 649 \mathrm{~S}}$ were obtained by electroporation in $\mathrm{KAx}-3$ cells of the ${ }_{\text {myc }} \mathrm{PTP} 3$ and ${ }_{\text {myc }} \mathrm{PTP} 3 \Delta^{\mathrm{C} 649 \mathrm{~S}}$ overexpressing constructs $\left(\mathrm{G} 418^{\mathrm{R}}\right)$ derived from the work of the Firtel laboratory [27]. All Dictyostelium strains were grown in Petri dishes or in shaking culture at $21^{\circ} \mathrm{C}$ in the presence of appropriate antibiotics in maltose-containing axenic medium [40] except for $\mathrm{Ax}-2$ and $d s t \mathrm{C}^{-}$that were 
grown in HL5 medium (Formedium, UK) supplemented with $14 \mathrm{~g} / \mathrm{l}$ glucose.

\section{Stress response activation}

Cells were harvested in log-phase from shaking cultures and resuspended in nutritive medium at $10^{7}$ cells $/ \mathrm{ml}$. After $1 \mathrm{~h} 30$-recovery in shaking suspension at $21^{\circ} \mathrm{C}$, cells were subjected to different stress conditions: heat shock at $32^{\circ} \mathrm{C}$ or sorbitol, $\mathrm{NaCl}$, glucose, glycerol, carbonyl cyanide 4-(trifluoromethoxy)phenylhydrazone (FCCP, Sigma-Aldrich, Saint Quentin Fallavier, France), $\mathrm{CdCl}_{2}$ and $\mathrm{H}_{2} \mathrm{O}_{2}$ (Sigma-Aldrich) at concentrations indicated in the text. For treatment with sorbitol, glucose, $\mathrm{NaCl}$ and glycerol, $10 \times$ stocks diluted in appropriate medium depending on the experiment (nutritive medium or phosphate buffer) were used. For heat shock experiments, cells were transferred to a $32^{\circ} \mathrm{C}$ shaking water bath. Samples of $200 \mu \mathrm{l}$ were removed just prior (t0) and during stress application as a function of time. Cells were rapidly centrifuged, resuspended in denaturing buffer (60 mM Tris-HCl, pH 6.8, 100 mM DTT, 6\% glycerol, 2\% SDS plus traces of bromophenol blue) and boiled for $3 \mathrm{~min}$ at $94^{\circ} \mathrm{C}$. To test the contribution of the cytoskeleton, cells were treated with $5 \mu \mathrm{M}$ latrunculin B (SigmaAldrich) or $10 \mu \mathrm{M}$ cytochalasin A (Sigma-Aldrich) and DMSO was used as control. 8-Br-cAMP (20 mM) (Enzo Life Sciences, Villeurbanne, France), 8-Br-cGMP $(20 \mathrm{mM})$ (Enzo) and thapsigargin $(10 \mu \mathrm{M})$ (Alomone Labs, Jerusalem, Israel) were used to test the impact of an increase in cAMP, cGMP and an elevation of intracellular calcium respectively. For experiments performed on adherent cells, stress was applied after $1 \mathrm{~h} 30$ of recovery, by removal of the nutritive medium and addition of fresh medium containing the appropriate concentration of stressor.

\section{Western blot}

Protein samples corresponding to $2 \times 10^{5}$ cells were separated by SDS-PAGE and transferred on PVDF membranes. AdcA was detected using the guinea-pig antiAdcA antibody (COB25) [16] in TBS-0.05\% Tween-20 containing 1\% BSA. STATc phosphorylation status was followed using the monoclonal phospho-specific (CP22) or non phospho-specific (7H3) antibodies as described [41]. The anti-phosphoTyr antibody PY20 used to detect Tyr53-phosphorylated actin was from SantaCruz (Clini Sciences, Nanterre, France). The anti-GFP (clones 7.1 and 13.1) and the anti-myc 9E10 antibodies were purchased from Roche Diagnostics (Meylan, France). Line scans and blot analyses were done with ImageJ software.

\section{Fluid-phase endocytosis assay}

Cells were resuspended at the concentration of $10^{7}$ cells $/ \mathrm{ml}$ in axenic medium. FITC-dextran $(2 \mathrm{mg} / \mathrm{ml}$ final $)$ and sorbitol (100, 200 and $400 \mathrm{mM}$ final) or cytochalasin A $(10 \mu \mathrm{M})$ were added simultaneously to the suspension. Samples of $10^{7}$ cells were removed as a function of time and transferred in ice-cold axenic medium containing the same concentration of sorbitol. After 3 washes, cells were resuspended in $1 \mathrm{ml}$ of $40 \mathrm{mM}$ Mes- $\mathrm{Na} \mathrm{pH}$ 6.5, counted rapidly and lysed by addition

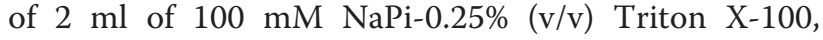
$\mathrm{pH}$ 10. The fluorescence intensity was measured at $\lambda_{\mathrm{ex}}$ $470 \mathrm{~nm}$ and $\lambda_{\mathrm{em}} 520 \mathrm{~nm}$. Data were converted into an equivalent volume of internalized fluid using a calibration curve [42].

\section{Live cell imaging and immunofluorescence}

Cells were let to adhere on glass coverslips for $1 \mathrm{~h} 30 \mathrm{in}$ axenic medium and subjected to stress treatment as indicated. For live cell imaging, cells were observed directly by DIC or fluorescence microscopy. In that latter case, LOFLO nutritive medium (Formedium) was used because of a reduced autofluorescence compared to the original medium. For immunostaining, cells were fixed in axenic medium containing $4 \%$ paraformaldehyde (PFA) and 0.1\% Triton X-100 for 10 min. After washes in PBS and $1 \mathrm{~h}$ incubation in PBS-0.5\% BSA, cells were then incubated with the anti-STATc $(7 \mathrm{H} 3)$ antibodies in PBS-0.5\% BSA at room temperature for $1 \mathrm{~h}$, washed three times in PBS-0.1\% Tween 20 and incubated with Alexa 488-coupled secondary antibodies (Molecular Probes/Life technologies, Saint-Aubin, France) for an additional hour. Actin was stained using Alexa 594-phalloidin (Molecular Probes). Cells were observed directly after three washes in PBS-Tween. Images were acquired on an Axiovert $200 \mathrm{M}$ Zeiss microscope equipped with a Piezo unit. The Axiovision software was used for image acquisition, deconvolution of z-stacks and maximal intensity z-projections.

\section{Phosphatase treatment}

Dephosphorylation assays using the CIP phosphatase (Promega, Charbonnières, France) were performed on SDS denatured samples. An aliquot corresponding to $2 \times 10^{5}$ cells was diluted 20 -fold in $50 \mathrm{mM}$ Tris- $\mathrm{HCl}$ $\mathrm{pH}$ 8.8, $0.66 \mathrm{mM} \mathrm{MgSO}, 1 \mathrm{mM} \mathrm{MgCl} 2,0.1 \mathrm{mM} \mathrm{ZnCl} 2$ and $1 \mathrm{mM}$ spermidine. About 15 units of CIP were added and dephosphorylation was performed at $37^{\circ} \mathrm{C}$ for $30 \mathrm{~min}$. For each time-point, an aliquot receiving no enzyme was treated in parallel as a control. Proteins were precipitated by a $1 \mathrm{~h}$-incubation on ice after the addition of $10 \%$ trichloroacetic acid (TCA), centrifuged at $16000 \times g$ and resuspended in denaturing buffer containing $200 \mathrm{mM}$ Tris base. Dephosphorylation was assessed by the abolition of the electrophoretic mobility shift on $8 \%$ SDS-PAGE gels. 


\section{Additional file}

Additional file 1: Movie 1. KAx-3 cells response to $200 \mathrm{mM}$ sorbitol. $\mathrm{KAx}-3$ cells were let to adhere on a glass coverslip in nutritive medium and subjected ( $\mathrm{t}=-30 \mathrm{sec}$ ) to $200 \mathrm{mM}$ sorbitol. The movie was taken by time-lapse video microscopy using DIC optics and a $63 x$ objective. The time frame of the movie corresponds to approximately 9 min, with images taken every 10 seconds.

\section{Abbreviations}

GPCR: G-protein coupled receptor; ART: Arrestin-related trafficking adaptor; Adc: Amoebal arrestin-domain containing protein; Arrdc: Mammalian arrestin-domain containing protein; CIP: Calf intestine phosphatase; PFA: Paraformaldehyde.

\section{Competing interests}

The authors declare no conflict of interests.

\section{Authors' contributions}

$\mathrm{CH}, \mathrm{GK}$ and LA designed the study. $\mathrm{CH}, \mathrm{GK}$ and LA conducted the experiments. $\mathrm{CH}, \mathrm{GK}, \mathrm{TA}, \mathrm{JGW}$ and LA drafted the manuscript. All authors read and approved the manuscript.

\section{Acknowledgements}

We thank R.A. Firtel, S. Schuster, J. Hadwiger and the DictyStock Center for providing us with various null strains and DNA constructs. We thank Ludwig Eichinger and Sébastien Léon for constructive discussions and advices. This work was supported by the Commissariat à l'Energie Atomique et aux Energies Alternatives (CEA-France), the Université Joseph Fourier (UJFGrenoble, France), the Centre National pour la Recherche Scientifique (FR3425) and the Agence Nationale pour la Recherche (ANR-12-BSV6-0016-01 DYNOTEP) to the OdyCell team (LA) and by the Wellcome Trust Program Grant 082579/Z (JGW). C. Habourdin is the recipient of a PhD fellowship from the French Ministère de l'Enseignement Supérieur et de la Recherche.

\section{Author details}

${ }^{1}$ CEA, iRTSV, Laboratoire Biologie à Grande Echelle, F-38054 Grenoble, France. ${ }^{2}$ Université Joseph Fourier, F-38041 Grenoble, France. ${ }^{3}$ INSERM, U1038, F-38054 Grenoble, France. ${ }^{4}$ College of Life Sciences, Welcome Trust Biocentre, University of Dundee, DD1 5EH, Dundee, United Kingdom. ${ }^{5}$ CEA-Grenoble, Institut de Recherche en Technologies et Sciences pour le Vivant, Laboratoire de Biologie à Grande Echelle, Equipe OdyCell, 17 rue des Martyrs, 38054 Grenoble Cedex 09, France.

Received: 26 June 2013 Accepted: 6 November 2013 Published: 22 November 2013

\section{References}

1. Gurevich W, Gurevich EV, Cleghorn WM: Arrestins as multi-functional signaling adaptors. Handb Exp Pharmacol 2008, 186:15-37.

2. Luttrell LM, Gesty-Palmer D: Beyond desensitization: physiological relevance of arrestin-dependent signaling. Pharmacol Rev 2010, 62:305-330

3. Magalhaes AC, Dunn H, Ferguson SS: Regulation of GPCR activity, trafficking and localization by GPCR-interacting proteins. British J Pharmacol 2012, 165:1717-1736.

4. Shenoy SK, Lefkowitz RJ: beta-Arrestin-mediated receptor trafficking and signal transduction. Trends Pharmacol Sci 2011, 32:521-533.

5. Shukla AK, Xiao K, Lefkowitz RJ: Emerging paradigms of beta-arrestindependent seven transmembrane receptor signaling. Trends Biochem SCl 2011, 36:457-469.

6. Alvarez CE: On the origins of arrestin and rhodopsin. BMC Evol Biol 2008, 8:222.

7. Aubry L, Guetta D, Klein G: The arrestin fold: variations on a theme. Curr Genomics 2009, 10:133-142.

8. Lin CH, MacGurn JA, Chu T, Stefan CJ, Emr SD: Arrestin-related ubiquitinligase adaptors regulate endocytosis and protein turnover at the cell surface. Cell 2008, 135:714-725.
9. Herranz S, Rodriguez JM, Bussink HJ, Sanchez-Ferrero JC, Arst HN Jr, Penalva $\mathrm{MA}$, Vincent $\mathrm{O}$ : Arrestin-related proteins mediate $\mathrm{pH}$ signaling in fungi. Proc Natl Acad Sci USA 2005, 102:12141-12146.

10. Becuwe M, Vieira N, Lara D, Gomes-Rezende J, Soares-Cunha C, Casal M, Haguenauer-Tsapis R, Vincent O, Paiva S, Leon S: A molecular switch on an arrestin-like protein relays glucose signaling to transporter endocytosis. J Cell Biol 2012, 196:247-259.

11. Hatakeyama R, Kamiya M, Takahara T, Maeda T: Endocytosis of the aspartic acid/glutamic acid transporter Dip5 is triggered by substrate-dependent recruitment of the Rsp5 ubiquitin ligase via the arrestin-like protein Aly2. Mol Cell Biol 2010, 30:5598-5607.

12. Merhi A, Andre B: Internal amino acids promote Gap1 permease ubiquitylation via TORC1/Npr1/14-3-3-dependent control of the Bul arrestin-like adaptors. Mol Cell Biol 2012, 32:4510-4522.

13. Nikko E, Pelham HR: Arrestin-mediated endocytosis of yeast plasma membrane transporters. Traffic 2009, 10:1856-1867.

14. Nabhan JF, Pan H, Lu Q: Arrestin domain-containing protein 3 recruits the NEDD4 E3 ligase to mediate ubiquitination of the beta2-adrenergic receptor. EMBO Rep 2010, 11:605-611.

15. Shea FF, Rowell JL, Li Y, Chang TH, Alvarez CE: Mammalian alpha arrestins link activated seven transmembrane receptors to Nedd4 family E3 ubiquitin ligases and interact with beta arrestins. PLoS One 2012, 7:e50557.

16. Guetta D, Langou K, Grunwald D, Klein G, Aubry L: FYVE-dependent endosomal targeting of an arrestin-related protein in amoeba. PLOS One 2010, 5:e15249.

17. Na J, Tunggal B, Eichinger L: STATC is a key regulator of the transcriptional response to hyperosmotic shock. BMC Genomics 2007, 8:123.

18. Araki T, Tsujioka M, Abe T, Fukuzawa M, Meima M, Schaap P, Morio T, Urushihara H, Katoh M, Maeda M, et al: A STAT-regulated, stress-induced signalling pathway in Dictyostelium. J Cell Sci 2003, 116:2907-2915.

19. Araki T, van Egmond WN, van Haastert PJ, Williams JG: Dual regulation of a Dictyostelium STAT by cGMP and $\mathrm{Ca}^{2+}$ signalling. J Cell Sci 2010, 123:837-841.

20. Howard PK, Sefton BM, Firtel RA: Tyrosine phosphorylation of actin in Dictyostelium associated with cell-shape changes. Science 1993, 259:241-244.

21. Ott A, Oehme F, Keller H, Schuster SC: Osmotic stress response in Dictyostelium is mediated by CAMP. EMBO J 2000, 19:5782-5792.

22. Pintsch T, Satre M, Klein G, Martin JB, Schuster SC: Cytosolic acidification as a signal mediating hyperosmotic stress responses in Dictyostelium discoideum. BMC Cell Biol 2001, 2:9.

23. Roelofs J, Van Haastert PJ: Characterization of two unusual guanylyl cyclases from Dictyostelium. J Biol Chem 2002, 277:9167-9174.

24. Schuster SC, Noegel AA, Oehme F, Gerisch G, Simon Ml: The hybrid histidine kinase DokA is part of the osmotic response system of Dictyostelium. EMBO J 1996, 15:3880-3889.

25. Kuwayama H, Ecke M, Gerisch G, Van Haastert PJ: Protection against osmotic stress by cGMP-mediated myosin phosphorylation. Science 1996, 271:207-209.

26. Oyama M: cGMP accumulation induced by hypertonic stress in Dictyostelium discoideum. J Biol Chem 1996, 271:5574-5579.

27. Gamper M, Howard PK, Hunter T, Firtel RA: Multiple roles of the novel protein tyrosine phosphatase PTP3 during Dictyostelium growth and development. Mol Cell Biol 1996, 16:2431-2444.

28. Araki T, Langenick J, Gamper M, Firtel RA, Williams JG: Evidence that DIF-1 and hyper-osmotic stress activate a Dictyostelium STAT by inhibiting a specific protein tyrosine phosphatase. Development 2008, 135:1347-1353.

29. Araki T, Williams JG: Perturbations of the actin cytoskeleton activate a Dictyostelium STAT signalling pathway. Eur J Cell Biol 2012, 91:420-425

30. Ma H, Gamper M, Parent C, Firtel RA: The Dictyostelium MAP kinase kinase DdMEK1 regulates chemotaxis and is essential for chemoattractantmediated activation of guanylyl cyclase. EMBO J 1997, 16:4317-4332

31. Gamper M, Kim E, Howard PK, Ma H, Hunter T, Firtel RA: Regulation of Dictyostelium protein-tyrosine phosphatase-3 (PTP3) through osmotic shock and stress stimulation and identification of pp 130 as a PTP3 substrate. J Biol Chem 1999, 274:12129-12138.

32. Kortholt A, van Egmond WN, Plak K, Bosgraaf L, Keizer-Gunnink I, van Haastert PJ: Multiple regulatory mechanisms for the Dictyostelium Roco protein GbpC. J Biol Chem 2012, 287:2749-2758. 
33. Goldberg JM, Manning G, Liu A, Fey P, Pilcher KE, Xu Y, Smith JL: The Dictyostelium kinome - analysis of the protein kinases from a simple model organism. PLoS Genet 2006, 2:e38.

34. Lefkowitz RJ, Rajagopal K, Whalen EJ: New roles for beta-arrestins in cell signaling: not just for seven-transmembrane receptors. Mol Cell 2006, 24:643-652.

35. Nikko E, Sullivan JA, Pelham HR: Arrestin-like proteins mediate ubiquitination and endocytosis of the yeast metal transporter Smf1. EMBO Rep 2008, 9:1216-1221.

36. Lin FT, Chen W, Shenoy S, Cong M, Exum ST, Lefkowitz RJ: Phosphorylation of beta-arrestin2 regulates its function in internalization of beta(2)-adrenergic receptors. Biochemistry 2002, 41:10692-10699.

37. Lin FT, Krueger KM, Kendall HE, Daaka Y, Fredericks ZL, Pitcher JA, Lefkowitz $\mathrm{RJ}$ : Clathrin-mediated endocytosis of the beta-adrenergic receptor is regulated by phosphorylation/dephosphorylation of beta-arrestin1. J Biol Chem 1997, 272:31051-31057.

38. Lin FT, Miller WE, Luttrell LM, Lefkowitz RJ: Feedback regulation of beta-arrestin 1 function by extracellular signal-regulated kinases. J Biol Chem 1999, 274:15971-15974.

39. Kim YM, Barak LS, Caron MG, Benovic JL: Regulation of arrestin-3 phosphorylation by casein kinase II. J Biol Chem 2002, 277:16837-16846.

40. Watts DJ, Ashworth JM: Growth of myxamoebae of the cellular slime mould Dictyostelium discoideum in axenic culture. Biochem J 1970, 119:171-174.

41. Fukuzawa M, Araki T, Adrian I, Williams JG: Tyrosine phosphorylationindependent nuclear translocation of a Dictyostelium STAT in response to DIF signaling. Mol Cell 2001, 7:779-788.

42. Aubry L, Klein G, Martiel JL, Satre M: Kinetics of endosomal pH evolution in Dictyostelium discoideum amoebae. Study by fluorescence spectroscopy. J Cell Sci 1993, 105:861-866.

doi:10.1186/1478-811X-11-91

Cite this article as: Habourdin et al:: The arrestin-domain containing protein AdcA is a response element to stress. Cell Communication and Signaling 2013 11:91.

\section{Submit your next manuscript to BioMed Central and take full advantage of:}

- Convenient online submission

- Thorough peer review

- No space constraints or color figure charges

- Immediate publication on acceptance

- Inclusion in PubMed, CAS, Scopus and Google Scholar

- Research which is freely available for redistribution 